\title{
Bagaimana Penguasaan Konsep Siswa pada Materi Fluida Statis?
}

\author{
Atika Isnaining Dyah ${ }^{1}$, Supriyono Koes $\mathrm{H}^{1}$, Hari Wisodo ${ }^{1}$ \\ ${ }^{1}$ Pendidikan Fisika-Universitas Negei Malang
}

\section{INFO ARTIKEL}

\section{Riwayat Artikel:}

Diterima: 12-03-2019

Disetujui: 15-08-2019

Kata kunci:
concept mastery;
static fluid;
penguasaan konsep;
fluida statis

\footnotetext{
Alamat Korespondensi:

Atika Isnaining Dyah

Pendidikan Fisika

Universitas Negeri Malang

Jalan Semarang 5 Malang

E-mail: atikaisnainingdyah@gmail.com
}

\begin{abstract}
ABSTRAK
Abstract: The purpose of this study is to determine the increase of mastery concept in static fluid in inquiry learning with theoretical empirical reviews. The research method uses descriptive analysis. The research subjects consisted of 31 students of SMAN 9 Malang. The measurement instrument is a concept of mastery test questions in the form of a multiple choice of 15 items. The calculation of the question reliability is 0.588 with quite high criteria. The results showed that there was an increase in mastery of the concept of static fluid. The results of the N-gain calculation show that $58 \%$ of students are in the upper medium category. This finding indicates that IDAET learning can improve mastery of the concept of static fluid.
\end{abstract}

\begin{abstract}
Abstrak: Tujuan penelitian ini adalah untuk mengetahui peningkatan penguasaan konsep fluida statis dalam pembelajaran inquiry-discovery dengan tinjauan empiris teoritis. Metode penelitian menggunakan analisis deskriptif. Subjek penelitian terdiri atas 31 siswa SMAN 9 Malang. Instrumen pengukuran berupa soal tes penguasaan konsep dalam bentuk pilihan ganda sebanyak 15 butir. Perhitungan reliabilitas soal sebesar 0,588 dengan kriteria cukup tinggi. Hasil penelitian menunjukkan bahwa terjadi peningkatan penguasaan konsep fluida statis. Hasil perhitungan N-gain diperoleh bahwa 58\% siswa berada pada kategori medium atas. Temuan ini mengindikasikan bahwa pembelajaran IDAET dapat meningkatkan penguasaan konsep fluida statis.
\end{abstract}

Tujuan pembelajaran fisika pada jenjang SMA salah satunya adalah siswa dapat menguasai konsep dengan baik (Sutopo, 2016). Kemampuan siswa dalam memaknai dan memahami konsep, baik konsep yang diperoleh secara teori maupun konsep yang telah diterapkan dalam kehidupan sehari-hari merupakan wujud dari siswa menguasai konsep dengan baik. Namun dalam penelitian (Handhika, Huriawati, \& Fitriani, 2017) menyimpulkan bahwa penguasaan konsep siswa SMA cenderung rendah. Kecenderungan tersebut dikarenakan banyak siswa yang merasa kesulitan dalam memahami konsep dalam pembelajaran (Ozkan \& Selcuk, 2016). Jumlah siswa yang merasa kesulitan dalam memahami konsep akan lebih banyak jika siswa mempunyai konsep yang berbeda tentang materi yang akan dipelajari (Miller, Lasry, Chu, \& Mazur, 2013). Siswa juga cenderung menggunakan persamaan atau rumus-rumus dalam mendapatkan solusi kuantitatif dari permasalahan dan sering melupakan konsep yang ada.

Materi fisika yang sulit dipahami hingga menyebabkan penguasaan konsep siswa menjadi rendah salah satunya adalah materi fluida statis. Beberapa kesulitan siswa yang terungkap dalam mempelajari materi fluida statis antara lain, (1) siswa kesulitan dalam mengidentifikasi gaya yang bekerja pada fluida dan menghubungkan gaya tersebut dengan tekanan (Loverude, Heron, \& Kautz, 2010), (2) siswa kesulitan dalam menentukan gaya apung pada benda yang massa berbeda, benda yang mengapung pada zat cair yang berbeda, dan ketika memprediksikan benda dalam keadaan tenggelam dan mengapung (Heron, Loverude, Shaffer, \& McDermott, 2003; Loverude et al., 2010; Minogue \& Borland, 2016; Yin, Tomita, \& Shavelson, 2008).

Siswa dapat menguasai konsep dengan baik jika siswa memperoleh konsep-konsep melalui pengalaman langsung. Dalam membangun konsep, siswa dapat menggabungkan potongan-potongan konsep atau ide yang didapat selama pembelajaran berlangsung (Docktor \& Mestre, 2014). Dari penggabungan ide tersebut, siswa akan menguasai konsep yang lebih besar. Oleh sebab itu, untuk mengatasi kesulitan siswa yang dikarenakan penguasaan konsep siswa rendah, tidak cukup dengan hanya meningkatkan kemampuan konseptual saja. Namun, sistem pengajaran yang mendukung untuk juga diperlukan dalam mengatasi kesulitan tersebut. Salah satu Salah satu strategi pembelajaran yang dapat menunjang penguasaan konsep siswa menjadi tinggi adalah Inquiry-Discovery dengan tinjauan empiris teoritis (IDAET). 
Pembelajaran IDAET menuntut siswa untuk menemukan konsep melalui pengalaman langsung agar penguasaan konsep siswa meningkat. Pembelajaran IDAET merupakan gabungan dua strategi pembelajaran yaitu pembelajaran Inquiry dan Discovery. Penggabungan tersebut dilakukan karena dalam proses menemukan (Discovery) melibatkan perumusan dan pengujian hipotesis-hipotesis melalui penyelidikan (Inquiry), (Schunk, 2012; Tompo, Ahmad, \& Muris, 2016) sehingga dalam pembelajaran IDAET ini menekankan pengalaman langsung dalam berlajar. Melalui proses inquiry siswa menjadi aktif dalam kegiatan belajar, bereksperimen, mengambil data, menganalisa, menyimpulkan dan mengomunikasikan secara langsung (Srisawasdi \& Panjaburee, 2015) serta proses berpikir seperti ilmuwan untuk menghasilkan pengetahuan baru.

\section{METODE}

Metode penelitian yang digunakan ialah analisis deskriptif, dengan subjek penelitian sebanyak 31 siswa kelas XI SMAN 9 Malang pada materi fluida statis. Teknik pengumpulan data dilakukan dengan tes penguasaan konsep. Instrumen tes berupa pilihan ganda sebanyak 15 soal, dengan reliabilitas soal sebesar 0,588 dengan kriteria cukup tinggi. Sebelum diberikan perlakuan, siswa melaksanakan pretest sesuai dengan pengetahuan awal. Kemudian siswa diberi perlakuan menggunakan pembelajaran Inquiry-Discovery dengan tinjauan empiris teoritis dan selanjutnya melakukan posttest.

Teknik analisis data menggunakan analisis deskriptif dengan menganalisis jawaban pretest-posttes dengan menggunakan $N$-gain ternormlisasi untuk melihat peningkatan skor dari pretest ke posttes. Setelah mengetahui hasil peningkatan skor tes, selanjutnya dilakukan pengkodingan untuk mengetahui pergeseran jawaban atau pola pikir siswa setelah dilakukan pembelajaran Inquiry-Discovery dengan tinjauan empiris teoritis.

\section{HASIL}

Hasil analisis skor penguasaan konsep siswa yang didapat dari hasil pretest dan posttes secara statistik dapat dilihat pada tabel 1. Tabel 1 menunjukkan bahwa penguasaan konsep antara pretest dan posttes mengalami peningkatan, dimana skor posttes dengan rata-rata 68,74 lebih tinggi dibanding skor pretest dengan rata-rata 40 . Selanjutnya, dilakukan perhitungan nilai $N$-gain dan Cohen's d-effect size guna mengetahui kekuatan peningkatan penguasaan konsep dari skor pretest ke posttes. Hasil perhitungan nilai $\mathrm{N}$ gain ditunjukkan pada gambar 1.

\section{Tabel 1. Deskripsi Data Penguasaan Konsep}

\begin{tabular}{cccccc}
\hline Nilai & $\mathbf{N}$ & Minimum & Maksimum & Mean & Std. Dev \\
\hline Pretest & 31 & 7 & 56 & 40 & 12,36 \\
\hline Posttes & 31 & 47 & 100 & 68,74 & 11,99 \\
\hline
\end{tabular}

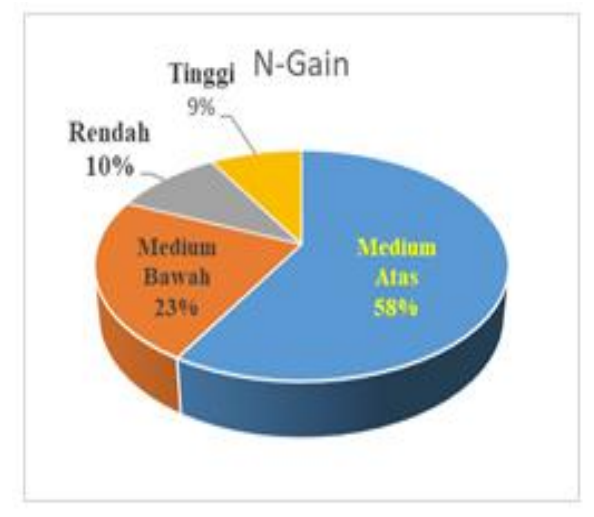

\section{Gambar 1. Distribusi N-Gain Siswa}

Gambar 1 menunjukkan bahwa nilai $\mathrm{N}$ gain ternormalisasi siswa paling banyak berada pada kriteria medium atas sebanyak 58\% dan paling sedikit pada kriteria tinggi sebesar 9\%. Perhitungan Nilai N-Gain berdasarkan skor rata-rata siswa diperoleh hasil sebesar 0,48 dengan kriteria medium atas. Perhitungan nilai rata-rata Cohen's d-effect size ditunjukkan pada tabel 2 .

Tabel 2 menunjukkan bahwa kekuatan peningkatan penguasaan konsep siswa mencapai nilai cohen d-effect size sebear 2,36 dengan kriteria lebih besar dari standar. Hal ini menunjukkan kekuatan perlakuan pada pembelajaran inquiry discovery dengan tinjauan empiris teoritis berada pada kategori lebih besar dari standar dalam meningkatkan penguasaan konsep. 
Tabel 2. Hasil Perhitungan N-Gain Pretest-Posttes Berdasarkan Rata-Rata Skor Siswa

\begin{tabular}{cccccc}
\hline Mean Pre & Mean Post & SD pre & SD Post & D & Kategori \\
\hline 40 & 68,7 & 12,4 & 12 & 2,36 & Lebih besar dari standar \\
\hline
\end{tabular}

\section{PEMBAHASAN}

Berdasarkan hasil penelitian, ditemukan bahwa penguasaan konsep siswa rata-rata mengalami peningkatan pada setiap soal. Akan tetapi, nilai N-gain dalam pembelajaran belum mencapai kriteria tinggi. Oleh sebab itu, perlu dieksplorasi secara mendalam mengenai kesulitan apa saja yang dialami siswa sehingga peningkatan penguasaan konsep berada pada kriteria medium atas. Salah satu kesulitan siswa dalam materi fluida statis tampak pada hubungan gaya apung dengan massa benda. Karena pada soal ini, banyak siswa mengalami miskonsepsi pada saat pretest dan terjadi pergeseran jawaban pada saat posttest. Pergeseran jawaban ini dapat dikatakan sebagai pergeseran pola pikir siswa. Soal yang dimaksud disajikan pada gambar 2.

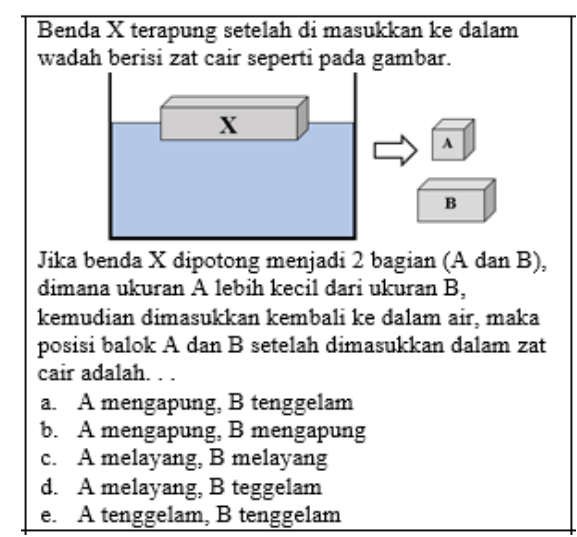

\section{Gambar 2. Soal Penerapan Hukum Archimedes}

Soal pada gambar 2 merupakan soal penerapan dari hukum Archimedes. Dalam soal diberikan gambar balok yang mengapung dalam wadah kemudian dipotong menjadi dua bagian, siswa diminta untuk menganalisis perbandingan massa dan gaya apung pada gejala terapung, melayang, dan tenggelam berdasarkan hukum Archimedes. Hasil analisis crosstabulation jawaban siswa disajikan pada tabel 3 .

Tabel 3. Hasil Crosstabulasi Jawaban Siswa pada Pretest-Posttes Soal Hukum Archimedes

\begin{tabular}{cccccc}
\hline & & & \multicolumn{2}{c}{ Posttest } & \multirow{2}{*}{ Total } \\
\cline { 3 - 5 } & & & B & D & \\
\hline \multirow{3}{*}{} & $\mathrm{A}$ & Jumlah & 16 & 0 & 16 \\
\cline { 2 - 5 } & & \% dari Total & $51,6 \%$ & $0 \%$ & $51,6 \%$ \\
\cline { 2 - 5 } & $\mathrm{B}$ & Jumlah & 11 & 0 & 11 \\
\cline { 2 - 5 } & & $\%$ dari Total & $35,5 \%$ & $0 \%$ & $35,5 \%$ \\
\cline { 2 - 5 } & $\mathrm{C}$ & Jumlah & 1 & 0 & 1 \\
\cline { 2 - 5 } & & $\%$ dari Total & $3,2 \%$ & $0 \%$ & $3,2 \%$ \\
\cline { 2 - 5 } & $\mathrm{D}$ & Jumlah & 2 & 1 & 3 \\
\cline { 2 - 5 } & \multirow{2}{*}{ Total } & \% dari Total & $6,5 \%$ & $3,2 \%$ & $9,7 \%$ \\
\cline { 2 - 5 } & Jumlah & 30 & 1 & 31 \\
\hline & \% dari Total & $96,8 \%$ & $3,2 \%$ & $100 \%$ \\
\hline
\end{tabular}

Berdasarkan tabel 3 terlihat sebanyak 20 siswa mengubah jawaban dari pretest ke posttest dengan rincian sebagai berikut, 16 siswa (51,6\%) menggeser jawaban dari A menjadi B, 1 siswa (3,2\%) menggeser jawaban dari C menjadi B, 2 siswa (6,5) menggeser jawaban dari D menjadi B. terdapat siswa yang mempertahankan jawaban saat pretest dan posttes dengan rincian sebagai berikut, 11 siswa $(35,5)$ bertahan pada jawban B dan 1 siswa $(3,2 \%)$ yang bertahan pada jawaban D. Pergeseran jawaban yang paling banyak pada siswa yang memilih jawaban dengan opsi A pada saat pretest dan bergeser menjadi jawaban dengan opsi B pada saat posttest. Pada saat pretes, siswa yang menjawab opsi A beranggapan bahwa massa memengaruhi besar gaya apung. Padahal massa jenis zat cair dan volume bendalah yang memengaruhi besar gaya apung bukan massa benda. Anggapan 
tersebut dikarenakan siswa tidak meninjau pertanyaan dari segi konseptual. Namun, dalam penelitian masih ditemukan satu siswa yang bertahan pada jawaban yang salah. Hal ini disebabkan siswa banyak yang masih belum memahami konsep secara benar, sehingga siswa masih beranggapan bahwa massa benda memengaruhi besar gaya apung. Hasil penelitian yang dilakukan oleh (Minogue \& Borland, 2016; Pratiwi, 2013) memperkuat hasil penelitian ini, dimana siswa mengalami kesulitan dalam menentukan gaya apung pada benda yang massa berbeda, benda yang mengapung pada zat cair yang berbeda, dan ketika memprediksikan benda dalam keadaan tenggelam dan mengapung.

Berdasarkan contoh soal yang disajikan pada gambar 2 menunjukkan bahwa penguasaan konsep siswa dapat meningkat melalui pembelajaran IDAET. Peningkatan penguasaan konsep siswa tidak hanya dilihat dari besar nilai N-gain, namun pergeseran jawaban siswa juga diperhitungkan karena pergeseran jawaban menunjukkan bahwa treatment dapat mengubah pola pikir siswa dan meningkatkan proses kognitif siswa.

\section{SIMPULAN}

Berdasarkan analisis data dan pembahasan yang telah dilakukan, maka dapat disimpulkan bahwa model pembelajaran IDAET dapat meningkatkan penguasaan konsep, peningkatan penguasaan konsep siswa berada pada kriteria medium atas, dan terdapat lebih dari 50\% siswa menggeser jawaban dari pretest ke posttes. Dari penelitian ini masih ditemukan siswa yang mengalami miskonsepsi. Oleh sebab itu, disarankan pada peneliti lain jika ingin melakukan penelitian lebih lanjut untuk menganalisis lebih dalam kesulitan yang dialami siswa, dan faktor yang menyebabkan siswa menggeser jawaban. Selain itu, guru sebaiknya menambah pertanyaan-pertanyaan konsep sebagai bahan diskusi untuk meningkatkan pemahaman siswa terhadap materi.

\section{DAFTAR RUJUKAN}

Docktor, J. L., \& Mestre, J. P. (2014). Synthesis of Discipline-Based Education Research in Physics. Physical Review Special Topics-Physics Education Research, 10(2), 020119.

Handhika, J., Huriawati, F., \& Fitriani, N. (2017). Force Concept Inventory (FCI) Representation of High School Students (SMA \& MA). Journal of Physics: Theories and Applications, 1(1), 29. https://doi.org/https://doi.org/10.20961/jphystheor-appl.v1i1.4706

Heron, P. R., Loverude, M. E., Shaffer, P. S., \& McDermott, L. C. (2003). Helping Students Develop an Understanding of Archimedes' Principle. II. Development of Research-Based Instructional Materials. American Journal of Physics, 71(11), 1188-1195. https://doi.org/doi: 10.1119/1.1607337

Loverude, M. E., Heron, P. R. L., \& Kautz, C. H. (2010). Identifying and Addressing Student Difficulties with Hydrostatic Pressure. American Journal of Physics, 78(1), 75-85.

Miller, K., Lasry, N., Chu, K., \& Mazur, E. (2013). Role of Physics Lecture Demonstrations in Conceptual Learning. Physical Review Special Topics-Physics Education Research, 9(2), 020113.

Minogue, J., \& Borland, D. (2016). Investigating Students' Ideas about Buoyancy and the Influence of Haptic Feedback. Journal of Science Education and Technology, 25(2), 187-202.

Ozkan, G., \& Selcuk, G. S. (2016). Facilitating Conceptual Change in Students' Understanding of Concepts Related to Pressure. European Journal of Physics, 37(5), 055702.

Pratiwi, A. (2013). Pembelajaran dengan Praktikum Sederhana untuk Mereduksi Miskonsepsi Siswa pada Materi Fluida Statis di Kelas XI SMA Negeri 2 Tuban. Inovasi Pendidikan Fisika, 2(3), 117-120.

Schunk, D. H. (2012). Teori-teori Pembelajaran: Perspektif Pendidikan (6th ed.). Yogyakarta: Pustaka Pelajar.

Srisawasdi, N., \& Panjaburee, P. (2015). Exploring Effectiveness of Simulation-Based Inquiry Learning In Science with Integration of Formative Assessment. Journal of Computers in Education, 2(3), 323-352.

Sutopo, S. (2016). Pemahaman Mahasiswa tentang Konsep-Konsep Dasar Gelombang Mekanik. Jurnal Pendidikan Fisika Indonesia, 12(1), 41-53.

Tompo, B., Ahmad, A., \& Muris, M. (2016). The Development of Discovery-Inquiry Learning Model to Reduce the Science Misconceptions of Junior High School Students. International Journal of Environmental and Science Education, 11(12), 5676-5686.

Yin, Y., Tomita, M. K., \& Shavelson, R. J. (2008). Diagnosing and Dealing with Student Misconceptions: Floating and Sinking. Science Scope, 31(8), 34. 